\title{
Enhancement of sedimentation and coagulation with static magnetic field
}

\author{
Marcin Zieliński ${ }^{1}$, Marcin Dębowski ${ }^{1, *}$, Anna Hajduk ${ }^{1}$, and Paulina Rusanowska ${ }^{1}$ \\ ${ }^{1}$ University of Warmia and Mazury in Olsztyn, Faculty of Environmental Sciences, Department of \\ Environment Engineering
}

\begin{abstract}
The static magnetic field can be an alternative method for wastewater treatment. It has been proved that this physical factor, accelerates the biochemical processes, catalyzes advanced oxidation, intensifies anaerobic and aerobic processes or reduces swelling of activated sludge. There are also reports proving the positive impact of the static magnetic field on the coagulation and sedimentation, as well as the conditioning and dewatering of sludge. In order to be applied in larger scale the published results should be verified and confirmed. In the studies, the enhancement of sedimentation by the static magnetic field was observed. The best sedimentation was noted in the experiment, where magnetizers were placed on activated sludge bioreactor and secondary settling tank. No effect of the static magnetic field on coagulation with the utilization of PIX 113 was observed. However, the static magnetic field enhanced coagulation with the utilization of PAX-XL9. The results suggest that increased sedimentation of colloids and activated sludge, can in practice mean a reduction in the size of the necessary equipment for sedimentation with an unchanged efficiency of the process.
\end{abstract}

\section{Introduction}

Due to constantly increasing volume of produced wastewater, changes of their composition and properties, a steady evolution and development in the methods used for wastewater treatment can be observed, nevertheless effective and economically viable methods are still sought [1]. An alternative to the methods used so far, can be an innovative technique based on the use of physical factor, that is a static magnetic field (SMF) [2]. The SMF causes selective ionization, changes in electrical conductance of solutions. Due to this the molecules are polarized and receive and appropriate charge.

It has been proved that this physical factor, accelerates the biochemical processes, catalyzes advanced oxidation, intensifies anaerobic and aerobic processes or reduces swelling of activated sludge $[1,3]$. There are also reports proving the positive impact of the SMF on the coagulation and sedimentation [4], as well as the conditioning and dewatering of sludge $[1,5]$. The results, however, require verification and confirmation.

These examples confirm that the use of the SMF might become an alternative and prospective method which allows to improve wastewater and sludge treatment. Economic

* Corresponding author: marcin.debowski@uwm.edu.pl 
considerations prompt to use magnetizers as assistive technology systems in water purification, wastewater and sludge treatment $[1,6]$. Magnetic fluids activators (MFA) are characterized by simple design. The greatest advantage is the lack of need to supply any form of energy and that the intensity of the magnetic field induction is not weakened over time [7]. For these reason such devices can be operated efficiently over many years. Moreover, magnetizers can be used in system without the need of adaptation period [1].

The aim of the study was to evaluate sedimentation and coagulation efficiency in the bioreactors and in the secondary settling tanks.

\section{Materials and methods}

The studies were carried out on a laboratory scale. The wastewater used in experiments was a model of dairy wastewater obtained by dissolving skimmed milk powder in tap water. The inoculum was activated sludge from municipal wastewater treatment plant in Olsztyn. The wastewater was characterized by chemical oxygen demand (COD) of $4181 \pm 890 \mathrm{mg} \mathrm{O}_{2} / \mathrm{dm}^{3}$, $\mathrm{pH}$ of $4.8 \pm 0.2$ and temperature $20.2 \pm 1.2^{\circ} \mathrm{C}$.

The studies were divided into two stages. In stage 1, the influence of the SMF on the sludge sedimentation in the secondary settling tank was investigated. The experiments were carried out in two activated sludge bioreactors, one with magnetizers placed on tank (series 1) and second one without magnetizers placed on tank (series 2) (Fig. 1). Raw wastewater were pumped to bioreactors from retention tank. The mixture of the activated sludge and the effluent was directed to the two secondary radial settling tanks, one with magnetizers placed (variant 1) and second one without magnetizers placed (variant 2).

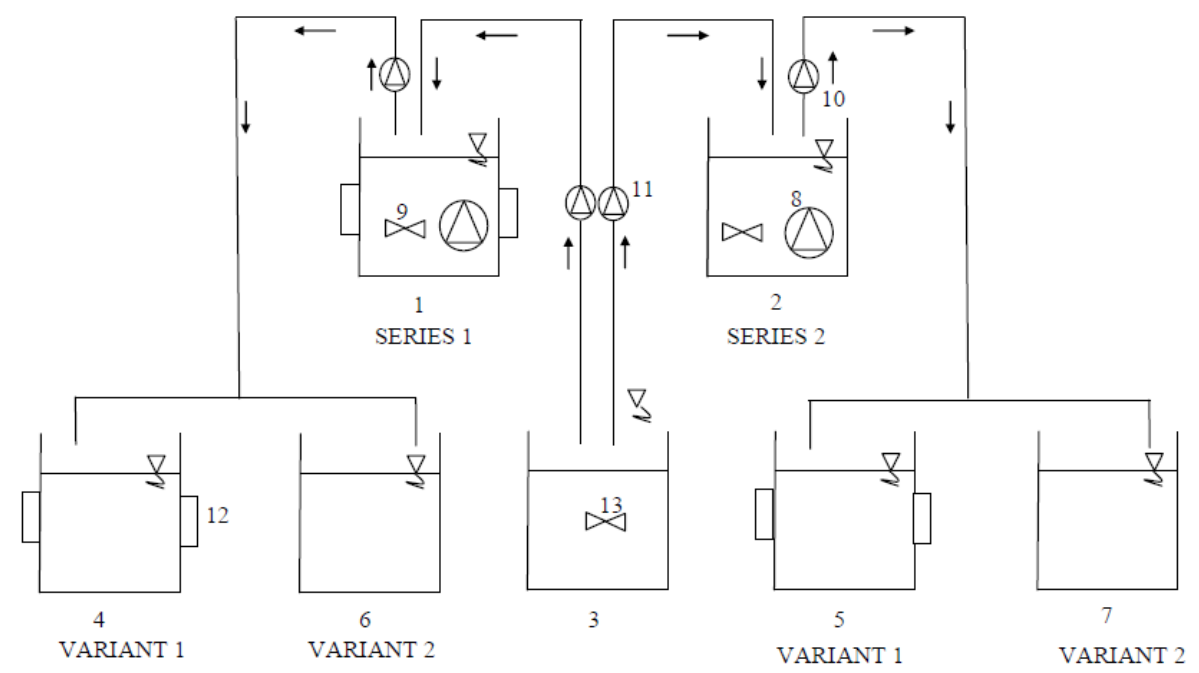

Fig. 1. Scheme of the experiments in stage $1(1-$ activated sludge bioreactor with MFA, 2 - activated sludge bioreactor without MFA, 3 - retention tank, 4, 5- secondary settling tanks with MFA, 6,7 - secondary settling tanks without MFA, 8 - aeration pump, 9 - stirrer, 10 - pump discarding effluent, 11 - pumps introducing raw wastewater, 12 - MFA, 13 - stirrer).

The technological parameters of the bioreactors and secondary settling tanks are shown in Table 1. The sedimentation was describe by the volume of activated sludge after 30 minutes in $1 \mathrm{dm}^{3}$ of wastewater $\left(\mathrm{cm}^{3} / \mathrm{dm}^{3}\right)$ and the sludge volume index $\left(\mathrm{SVI}_{30}\right)$ $\left(\mathrm{cm}^{3} / \mathrm{g}\right.$ TSS $)$. 
Table 1. Technological parameters of the bioreactors and the secondary settling tanks.

\begin{tabular}{|c|c|c|}
\hline Parameter & Unit & Value \\
\hline Bioreactor & \multicolumn{2}{|c|}{} \\
\hline Volume & $\mathrm{dm}^{3}$ & 4.5 \\
\hline Concentration of activated sludge & $\mathrm{g} \mathrm{TSS} / \mathrm{dm}^{3}$ & 3 \\
\hline Organic loading & $\mathrm{g} \mathrm{COD} / \mathrm{g} \mathrm{TSS} \cdot \mathrm{d}$ & 0.15 \\
\hline Hydraulic retention time & $\mathrm{day}$ & 22.5 \\
\hline Concentration of oxygen & $\mathrm{mg} \mathrm{O} 2 / \mathrm{dm}^{3}$ & 3.5 \\
\hline \multicolumn{2}{|c|}{ Secondary radial settling tank } \\
\hline Volume & $\mathrm{dm}^{3}$ & 0.04 \\
\hline Surface & $\mathrm{dm}^{2}$ & 0.02 \\
\hline Operating height & $\mathrm{dm}^{3}$ & 2 \\
\hline Hydraulic loading & $\mathrm{dm}^{3} / \mathrm{dm}^{2} \cdot \mathrm{h}$ & 10 \\
\hline Settling time & $\mathrm{h}$ & 0.5 \\
\hline
\end{tabular}

The magnetizers were placed directly on the circumferences of the bioreactor and secondary settling tank. The magnetizers were built of two parts forming a ring. Permanently magnetized ceramic frits in the MFA emitted the SMF. In order to increase the direct impact of SMF, a set consisting of two rings were placed on bioreactors. The parameters of the MFA were width of the ring of $65 \mathrm{~mm}$, height of the individual ceramic magnet of $45 \mathrm{~mm}$, weight of the individual ring of $1.25 \mathrm{~kg}$, and nominal diameter range of 90-110 mm. The maximal induction of SMF was 6000 Gauss $(0.6 \mathrm{~T})$.

In the stage 2, the effect of the SMF on coagulation was observed. The coagulation was carried out in the chambers. To the chamber the inorganic coagulants were dosed. After dosing of coagulant the rapid stirring, slow stirring (flocculation) and sedimentation take place. Basic technological parameters of the chambers are presented in Table 2.

Table 2. Technological parameters of coagulation chambers.

\begin{tabular}{|c|c|c|}
\hline Parameter & Unit & Value \\
\hline Volume & $\mathrm{dm}^{3}$ & 1 \\
\hline Surface & $\mathrm{dm}^{2}$ & 0.7 \\
\hline Height & $\mathrm{dm}$ & 1.4 \\
\hline Time of rapid stirring & $\mathrm{min}$. & 5 \\
\hline Intensity of rapid stirring & $\mathrm{rpm}$ & 200 \\
\hline Time of slow stirring & $\mathrm{min}$. & 20 \\
\hline Intensity of slow stirring & $\mathrm{rpm}$ & 30 \\
\hline Time of sedimentation & min. & 120 \\
\hline
\end{tabular}

The two series of experiments were done. In the series 1, the source of SMF was placed on coagulation chamber. In the series 2 , the coagulation chamber was operated without the magnets (control) (Fig 2.). The chambers were equipped with stirrer with adjustable speed. Each series was divided into two variants to test different type of the coagulant. Moreover, four different doses of the coagulants were investigated. 


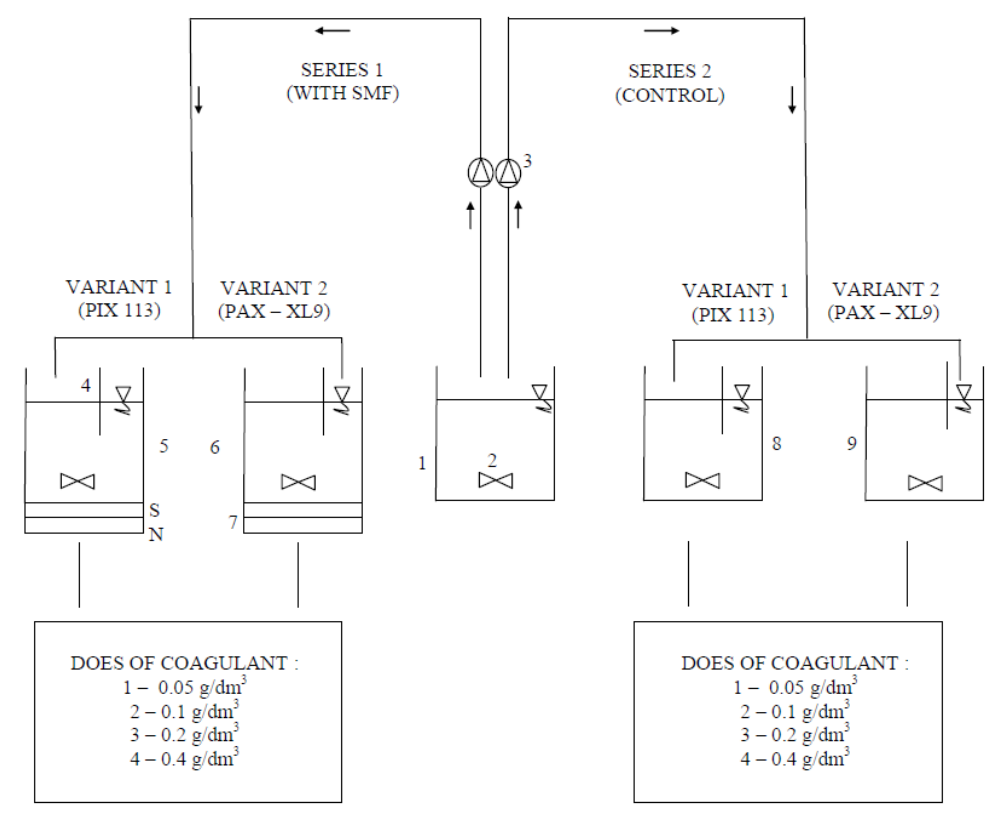

Fig 2. Scheme of the experiment in stage $2(1$ - retention tank, 2 - stirrer, 3 - pumps introducing raw wastewater, 4 - outlet for sample collecting, 5,6 - chambers with magnets, 7 - neodymium magnets, 8,9 - chambers without magnets (controls).

The criterion for separating variant was type of used inorganic coagulant. In the variant 1 , the ferric coagulant name PIX 113 was tested. In the variant 2, the aluminum coagulant name PAX - XL9 was tested. For both coagulants four doses were applied: $0.05 \mathrm{~g} / \mathrm{dm}^{3}$, $0.1 \mathrm{~g} / \mathrm{dm}^{3}, 0.2 \mathrm{~g} / \mathrm{dm}^{3}, 0.4 \mathrm{~g} / \mathrm{dm}^{3}$. The characteristics of the used coagulants is presented in Table 3.

Table 3. Chemical compositions of the coagulants.

\begin{tabular}{|c|c|}
\hline PIX 113 & PAX-XL9 \\
\hline Total Fe $11.8 \pm 0.4 \%$ & $\mathrm{Al}_{2} \mathrm{O}_{3} 8.5 \pm 0.4 \%$ \\
\hline $\mathrm{Fe}^{2+} 0.4 \pm 0.3 \%$ & $\mathrm{Al}_{2} 4.5 \pm 0.2$ \\
\hline $\mathrm{pH}<1$ & Chlorides $10.0 \pm 1.0 \%$ \\
\hline & $\mathrm{pH} 3.0 \pm 0.6 \%$ \\
\hline
\end{tabular}

In the 2 stage, the effect of the SMF on coagulation was provided by the use of permanent neodymium magnets. Magnets were directed up with the positive side, opposite to the charges of the most natural colloids (Fig. 2). The characteristics of the used neodymium magnets is shown in Table 4.

In order to assess the effectiveness of coagulation supported by the SMF, changes in concentration of the COD in 15 minute intervals were recorded. The standard dichromate method was used to determine the COD. During this method high temperature mineralizer HT200S and spectrophotometer UV-VIS DR 5000 were used. 
Table 4. Characteristics of neodymium magnets.

\begin{tabular}{|c|c|c|}
\hline Parameter & Unit & Value \\
\hline Diameter & $\mathrm{dm}$ & 0.7 \\
\hline Height & $\mathrm{dm}$ & 0.02 \\
\hline Energy density of magnetic field & $\mathrm{kJ} / \mathrm{dm}^{3}$ & $0.286-0.302$ \\
\hline Induction of remanence & $\mathrm{T}$ & $1.21-1.25$ \\
\hline Coercion $\mathrm{H}_{\mathrm{cB}}$ min & $\mathrm{kA} / \mathrm{m}$ & 899 \\
\hline Coercion $\mathrm{H}_{\mathrm{cJ}}$ min & $\mathrm{kA} / \mathrm{m}$ & 955 \\
\hline
\end{tabular}

Statistical analysis of the results was done with STATISTICA 10.0 PL. The hypothesis on the distribution of each analyzed variable was verified with the Shapiro-Wilk W test. The significance of differences between variables was stated with the use of one-way analysis of variance (ANOVA). The homogeneity of variance in groups was checked with the Levene's test. The significance of differences between analyzed variables was determined with the RIR Tukey test. Differences were found significant at $\alpha=0.05$.

\section{Results and discussion}

In the stage 1 the concentration of activated sludge in both series was about $3000 \mathrm{mg} \mathrm{TSS} / \mathrm{dm}^{3}$. Similar values were observed by Hattori et al. (2001). The authors suggest that the magnetic field with induction of $0.08 \mathrm{~T}$ seems to not affect the growth of activated sludge [7]. However, $\mathrm{Xu}$ and Sun (2008) observed that magnetic field with induction of $0.024 \mathrm{~T}$ and $0.06 \mathrm{~T}$ improved the quantity of mixed bacteria in medium. The authors also noted that propagation rate of mixed bacteria was the biggest at the SMF induction of $0.06 \mathrm{~T}$. From the presented results it appears that the enhancement of bacteria growth can be observed with magnetic induction lower then $0.1 \mathrm{~T}$. Whereas higher densities of magnetic field does not affect the growth of bacteria [5].

In the studies, the enhancement of sedimentation by the SMF was observed. The best sedimentation was noted in variant 1 of series 1 , where magnetizers were used on activated sludge bioreactor and secondary settling tank. The volume of the sludge after 30 minutes of sedimentation was $440 \pm 15 \mathrm{~cm}^{3} / \mathrm{dm}^{3}$ and $\mathrm{SVI}_{30}$ was $145.25 \pm 4.95 \mathrm{~cm}^{3} / \mathrm{g}$ (Fig. 3, 4). The application of magnetizers only on the activated sludge bioreactor decreased the sedimentation properties of the sludge. The volume of the sludge after 30 minutes of sedimentation and the $\mathrm{SVI}_{30}$ increased of $200 \mathrm{~cm}^{3} / \mathrm{dm}^{3}$ and $70 \mathrm{~cm}^{3} / \mathrm{g}$, respectively. The sedimentation of the activated sludge was decreased in the series 2 , when the activated sludge bioreactor was operated without influence of the SMF. The volume of the sludge after 30 minutes of sedimentation was $920 \pm 12.5 \mathrm{~cm}^{3} / \mathrm{dm}^{3}$ and $960 \pm 9.5 \mathrm{~cm}^{3} / \mathrm{dm}^{3}$ in the variant 3 and 4, respectively. Similar tendency was observed in case of the $\mathrm{SVI}_{30}$. Hattori et al. (2001) also used SMF to enhance to sludge sedimentation [7]. The authors applied the SMF with induction of $0.08 \mathrm{~T}$. In the experiment, their used the wastewater circulation system in which the activated sludge flow through magnetic field. The $\mathrm{SVI}_{30}$ observed by Hattori et al. (2001) was lower then in presented experiments and it was about $90 \mathrm{~cm}^{3} / \mathrm{g}$. The enhancement of sedimentation was also observed by Gokon et al. (2002). The authors have shown, that despite the higher concentration of the activated sludge, the smaller volume was occupied by the sludge after sedimentation in reactor with SMF in comparison to the control reactor [8]. Similar result were also observed for aerobic granular sludge. The magnetic field with induction of $48 \mathrm{mT}$, significantly decreased SVI from $77.32 \mathrm{~cm}^{3} / \mathrm{g}$ to $20.93 \mathrm{~cm}^{3} / \mathrm{g}$ [9]. 


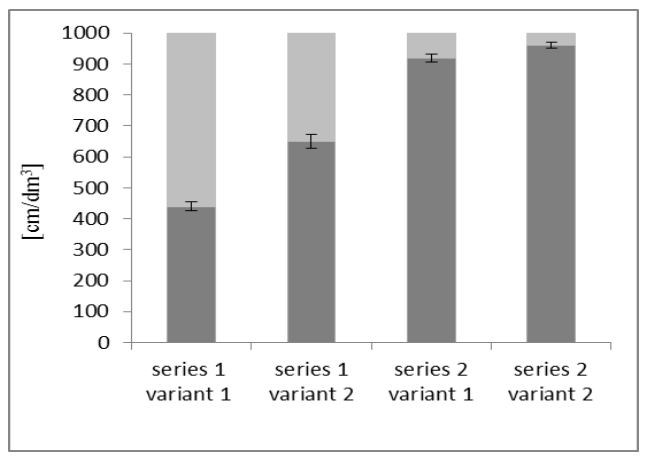

Fig. 3. The volume of the sludge after 30 minutes of sedimentation.

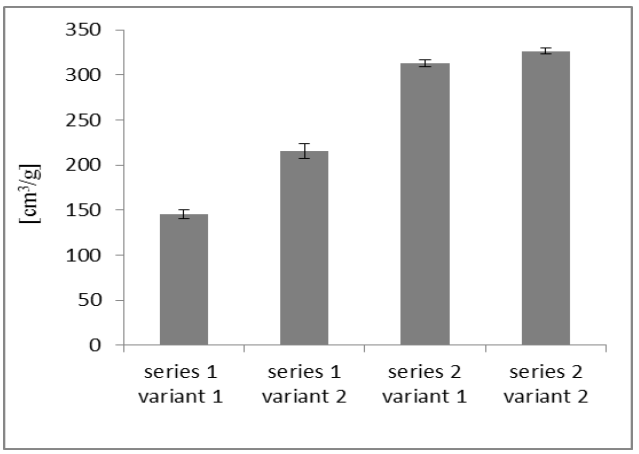

Fig. 4. The SVI30.

In stage 2, no effect of the SMF on coagulation with the utilization of PIX 113 was observed, only the increased dose of coagulant (from $0.05 \mathrm{gFe}^{3+} / \mathrm{dm}^{3}$ to $0.2 \mathrm{gFe}^{3+} / \mathrm{dm}^{3}$ ) enhanced coagulation. The efficiency of coagulation with SMF increased from $28 \pm 2.3 \%$ to $60 \pm 1.5 \%$, when the doses of coagulant were $0.05 \mathrm{gFe}^{3+} / \mathrm{dm}^{3}$ and $0.2 \mathrm{gFe}^{3+} / \mathrm{dm}^{3}$, respectively (Fig. 5). In case of the control chambers, the efficiency of coagulation increased from $26 \pm 2 \%$ to $57 \pm 1.2 \%$, when the doses of coagulant were $0.05 \mathrm{gFe}^{3+} / \mathrm{dm}^{3}$ and $0.2 \mathrm{gFe}^{3+} / \mathrm{dm}^{3}$, respectively. However, the SMF enhanced coagulation with the utilization of PAX-XL9. The significant differences were observed in the chambers, in which the dose of coagulant was from $0.1 \mathrm{gAl}^{3+} / \mathrm{dm}^{3}$ to $0.4 \mathrm{gAl}^{3+} / \mathrm{dm}^{3}$ (Fig. 6). The efficiency of coagulation enhanced by SMF was $52 \pm 1.3 \%, 61 \pm 0.8 \%, 64 \pm 0.6 \%$ for the doses of $0.1 \mathrm{gAl}^{3+} / \mathrm{dm}^{3}, 0.2 \mathrm{gAl}^{3+} / \mathrm{dm}^{3}, 0.4 \mathrm{gAl}^{3+} / \mathrm{dm}^{3}$, respectively. In control, the efficiency of coagulation was $45 \pm 2 \%, 54 \pm 1.7 \%$ and $58 \pm 1.5$ for the doses of $0.1 \mathrm{gAl}^{3+} / \mathrm{dm}^{3}, 0.2 \mathrm{gAl}^{3+} / \mathrm{dm}^{3}, 0.4 \mathrm{gAl}^{3+} / \mathrm{dm}^{3}$, respectively.

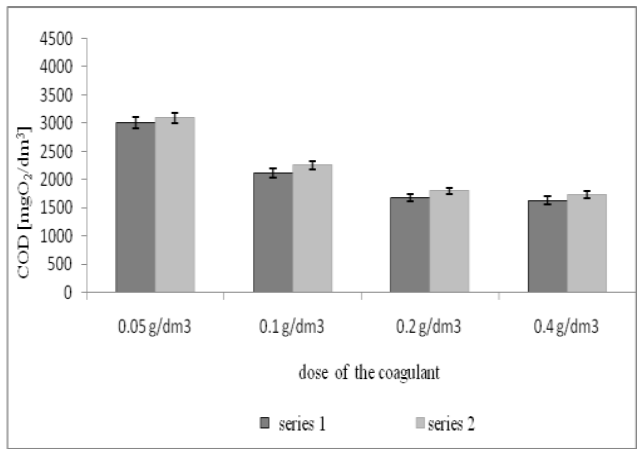

Fig. 5. The COD values depending on the dose of the coagulant PIX 113.

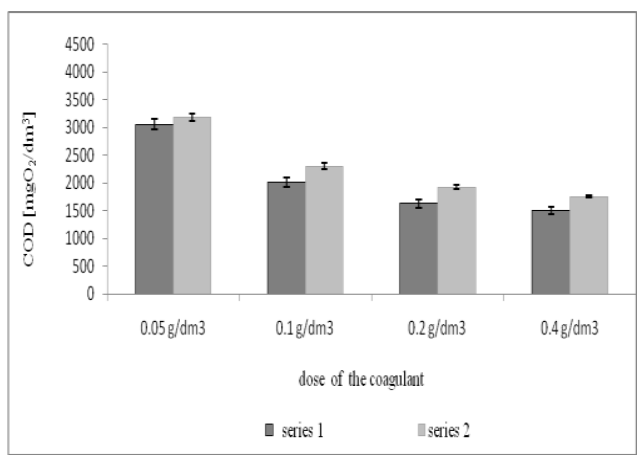

Fig. 6. The COD values depending on the dose of the coagulant PAX-XL9.

The impact of SMF on the rate of COD removal was only found in the case of the highest dose of coagulant PAX-XL9. The rate of the COD removal in the control was $73 \pm 9.26 \mathrm{mgO}_{2} / \mathrm{dm}^{3} \cdot \mathrm{min}$, while in the chamber with magnets it increased to $87 \pm 7.23 \mathrm{mgO}_{2} / \mathrm{dm}^{3} \cdot \mathrm{min}$. (Fig. 8) In the case of the coagulant PIX 113, the rate of COD removal was $74 \pm 7.85 \mathrm{mgO}_{2} / \mathrm{dm}^{3} \cdot \mathrm{min}$ in the control, and $79 \pm 11.77 \mathrm{mgO}_{2} / \mathrm{dm}^{3} \cdot \mathrm{min}$ in the chamber with magnets (Fig. 7) . 


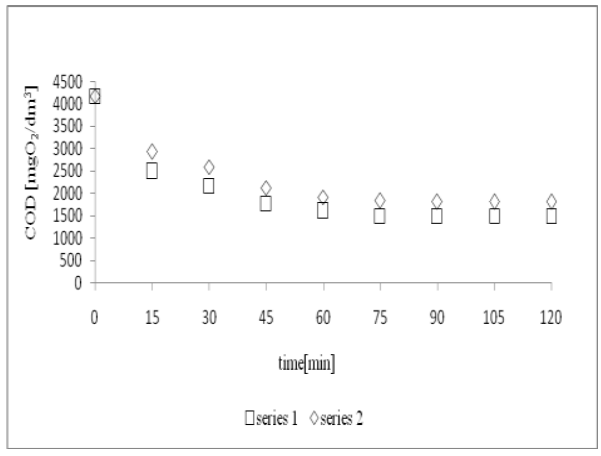

Fig. 7. The changes of COD after dosing 0.4 $\mathrm{gFe}^{3+} / \mathrm{dm}^{3}$ of PIX 113 .

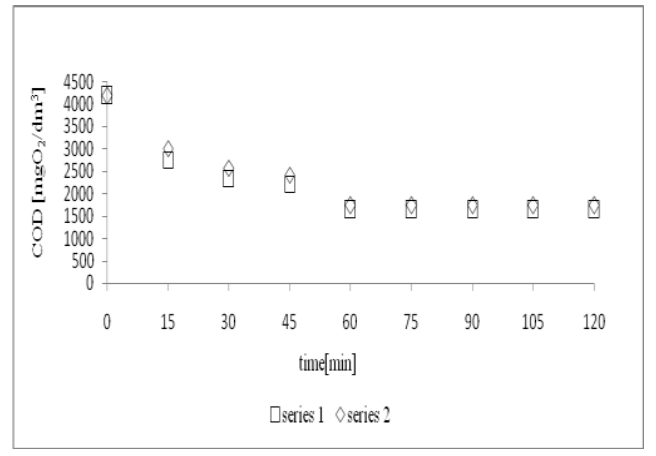

Fig. 8. The changes of COD after dosing $0.4 \mathrm{gAl}^{3+} / \mathrm{dm}^{3}$ of PAX-XL9.

Hattori et al. (2001) observed similar results with the utilization of coagulant PIX 113. The addition of $0.1 \% \mathrm{FeCl}_{3}$ to the reactors with SMF did not increased sedimentation properties. The authors explained that the sludge they used in the experiment had already $0.05-0.10 \% \mathrm{Fe} /$ dry weight. Therefore, the addition of $\mathrm{FeCl}_{3}$ might not be so influential on sedimentation enhancement with SMF [5]. The same observations was noted by Wang et al. (2012) [9].

\section{Conclusions}

The application of SMF led to significant enhancement of capability to sedimentation of activated sludge. It was found, that the best sedimentation properties had the activated sludge from bioreactor with SMF, which was concentrated in secondary settling tank with SMF. The volume of activated sludge increased of $560 \mathrm{~cm}^{3} / \mathrm{dm}^{3}$ in secondary settling tank without magnetizers and bioreactor without magnetizers.

The SMF improved the efficiency and rate of COD removal from wastewater after coagulation with coagulant PAX-XL9. The efficiency of coagulation increased of about 5\% by using magnets. The COD removal rate was dependent on the dose of coagulant and was the highest after the dose of $0.4 \mathrm{gAl}^{3+} / \mathrm{dm}^{3}$. However, no significant impact of the SMF on the technology results of coagulation with PIX 113 was observed. The results suggest that increased sedimentation of colloids and activated sludge, can in practice mean a reduction in the size of the necessary equipment for sedimentation with an unchanged efficiency of the process.

\section{References}

1. M. Krzemieniewski, M. Dębowski, M. Zieliński, Utilization of eletromagnetic microwave radiation nad static magnetic field in wastewater and sludge treatment (2002) (in Polish)

2. M. Zieliński, A. Cydzik-Kwiatkowska, M. Zielińska, M. Dębowski, P. Rusanowska, J. Kopańska, Water Air Soil. Pollut. 228, 126 (2017)

3. A. Yadollahpour, S. Rashidi, Z. Ghotbeddin, M. Jalilifar, Z. Rezaee, Jour. of Pure and Appiled Microbiol. 8, 5, 3711-3719 (2014)

4. H. Yavuz, S.S. Celebi, Enzyme and Microb. Techn. 26, 1, 22-27 (2000)

5. Y.B. Xu, S.Y. Sun, Biodegradation 19, 3, 455-462 (2008) 
6. M. Zieliński, M. Dębowski,M. Krzemieniewski, A. Brudniak, Environ. Prog. and Susta. Energy 34, 2, 427-41 (2014)

7. S. Hattori, M. Watanabe, T. Endo, H. Togii, K. Sasaki, World Jour. of Microb. and Biotech. 17, 279-285 (2001)

8. N. Gokon, A. Shimada A, H. Kaneko, Y. Tamaura, K. Ito, T. Ohara, J. Magn. and Magn. Mat. 238, 47-55 (2002)

9. X.H. Wang, M.H. Diao, Y. Yang, Y.J. Shi, M.M. Gao, S.G. Wang, Bioresour. Technol. 110, 105-10 (2012) 